\title{
Transversalizando a orientação sexual nos anos finais do ensino fundamental
}

\author{
Claudia Regina Neves Barboza1, Jerônimo Sartori² \\ ${ }^{1}$ Licenciada em Ciências Biológicas. Pós-graduada no curso de Especialização em Educação: \\ Interdisciplinaridade e Transversalidade, Campus São Gabriel - Unipampa. claudianevesbarboza@yahoo.com.br. \\ 2 Doutor em Educação pelo PPGEdu/Faced/UFRGS. Professor da UFFS, Campus Erechim. \\ jetori55@yaho.com.br.
}

\section{Resumo}

A escola é um espaço de convivência e de trocas de experiências que possibilita a socialização e apreensão de novas aprendizagens, oriundas do compartilhamento das diferentes culturas e da interação social que a escola propicia. É dever da escola, portanto, ofertar uma educação emancipatória, voltada para o desenvolvimento integral do educando. O presente trabalho trata de uma pesquisa de intervenção pedagógica acerca do tema transversal Orientação Sexual, nas séries finais do Ensino Fundamental (7º e $8^{\circ}$ anos), numa Escola Municipal de Ensino Fundamental, na cidade de São Gabriel/RS. A ação adotada referente ao tema transversal - Orientação Sexual - precisa ser considerada como um processo de intervenção metodológica, que se propõe a obter/fornecer informações sobre sexualidade, bem como organizar um espaço de reflexões e questionamentos sobre diferentes enfoques: importância da prevenção contra DSTs e gravidez indesejada, mudanças corporais, identidade, relações interpessoais, autoestima, relações de gênero, tabus, crenças e valores a respeito de relacionamentos, comportamentos sexuais e DSTs. Sexualidade é uma questão processual, uma questão de vivência e de experimentação. A construção do gênero e da sexualidade ocorre ao longo de toda a vida do sujeito. Apesar dos Parâmetros Curriculares Nacionais (PCNs) sofrerem críticas oriundas de diferentes pensadores e esferas da educação, é inegável que esses documentos instituíram a discussão acerca da educação sexual nas escolas. Cabe, então, a cada realidade projetar o alcance sobre o entendimento e o desvelamento dos corpos e da sexualidade latente entre os estudantes da Educação Básica.

Palavras-chave: Orientação sexual. Tema transversal. Intervenção pedagógica. PCNs.

\section{Abstract}

The learning space is a social ambient where experiences are traded, where means of diverse social interactions are possible, and where education provides the knowledge and the comprehension of different cultures. Therefore, it is the duty of the school to provide an emancipatory education, focused in integral development. The following work results from a pedagogic intervention research about Sexual Orientation, conducted in the final years of elementary school (seventh and eighth grade) at the Elementary Municipal School, in the city of São Gabriel, RS. The course of action chosen in response to the transversal theme of Sexual Orientation has to be seen as a process of methodological intervention, which gives and obtains information regarding sexuality, organizing a space open to reflection and questioning regarding different subjects: importance of prevention, bodily changes, identity, interpersonal relationships, selfesteem, gender roles, taboos, values and beliefs regarding relationships, sexual behaviors, and STDs. Sexuality is a processual matter, a question of living and experimenting. The construction of sexuality and gender occurs over the individual's whole life. In spite of the National Curriculum Standards (PCNs) being criticized by many educators, it's undeniable that these documents instituted the discussion on sexual education in schools. It's up to every different reality to find a way to promote the demystification and the understanding of our bodies and of our sexuality, something very lacking in basic education.

Keywords: Sexual orientation, transversal theme, pedagogic intervention, PCNs. 


\section{Introdução}

A escola é um espaço de convivência e de trocas de experiências que possibilita a socialização e apreensão de novas aprendizagens, oriundas do compartilhamento das diferentes culturas e da interação social que a escola propicia. É dever da escola, portanto, ofertar uma educação emancipatória, voltada para o desenvolvimento integral do educando.

Os Parâmetros Curriculares Nacionais (PCNs) orientam que os conteúdos didáticos não sejam apenas um acúmulo de informações, mas que configurem o respeito às potencialidades do alunocidadão; assim, a aprendizagem encerra em si criatividade, criticidade, diversidade, crescimento. $\mathrm{O}$ processo ensino-aprendizagem tem como foco o desenvolvimento das capacidades do educando, haja vista que ele é o sujeito da sua própria formação, em um processo interativo com os professores, a partir de suas vivências e do próprio conhecimento.

Os temas transversais, apresentados nos Parâmetros Curriculares Nacionais (PCNs), contemplam os conceitos e os valores básicos que se relacionam à democracia e ao exercício consciente da cidadania. Também, apresentam questões pertinentes à sociedade contemporânea como a ética, o meio ambiente, a saúde, o trabalho e o consumo, a orientação sexual e a pluralidade cultural. Os temas transversais não constituem disciplinas pontuais, são temas interdisciplinares que fazem parte da vida em sociedade em seus diferentes segmentos e espaços sociais. Por serem significativos, os temas transversais devem ser trabalhados de forma contextualizada, para que os alunos encontrem sentido naquilo que aprendem, e para que os educadores atentem para a necessidade da expressividade das temáticas sociais a serem construídas no ambiente escolar. Trabalhar os temas transversais representa um meio para promover a educação como ferramenta de transformação social.

Com base no esteio legal, ou seja, nos Parâmetros Curriculares Nacionais (PCNs), trabalhamos o tema transversal Orientação Sexual com o intuito de promover uma ação crítica, reflexiva e criativa, por meio de um projeto de intervenção nas turmas de $7^{\circ}$ e $8^{o}$ anos do Ensino Fundamental.

O projeto, desenvolvido numa escola municipal de ensino fundamental da cidade de São Gabriel/RS, trata de uma pesquisa documental, realizada por meio do levantamento de dados, através de um questionário e de uma intervenção pedagógica, referenciando a educação sexual na escola, em que foram envolvidos alunos e comunidade escolar. A escola campo de estudo foi criada em 18 de setembro de 1956, situada no perímetro urbano da cidade de São Gabriel. Este estabelecimento de ensino possui 182 alunos matriculados, nos turnos manhã e tarde. Conta, atualmente, com 14 professores, 02 funcionários, 05 auxiliares e 01 intérprete de libras, atendendo alunos de média e baixa renda, procedentes de diferentes bairros da cidade.

Partimos de um questionamento aberto-fechado para identificar características do comportamento sexual dos adolescentes participantes do projeto. O passo seguinte constituiu-se na intervenção propriamente dita: textos informativos, vídeos para discussão, jogos entre equipes da turma e das duas turmas envolvidas no estudo, confecção de murais e realização de palestras para alunos e demais membros da comunidade escolar, ministradas por alunos da Universidade Federal do Pampa (UNIPAMPA), em parceria com a Secretaria Municipal de Saúde. As palestras estiveram voltadas para os temas relacionados à prevenção e à saúde, bem como sobre a questão de orientação de gênero e preconceitos (palestra proferida por uma psicóloga). 


\section{Refletindo sobre a prática dos Temas Transversais na Educação Básica}

A práxis freireana entende que as relações sociais são produtoras da sociabilidade humana e que a humanização dessas práticas constitui condição fundamental para a educação. A autoconstrução do ser humano emancipado acontece no processo contínuo de ação-reflexão e de reflexão sobre a ação.

Se a escola deseja ter uma visão integrada das experiências vividas pelos alunos, buscando desenvolver o prazer pelo conhecimento, é necessário reconhecer que desempenha um papel importante na educação para uma sexualidade ligada à vida, à saúde, ao prazer e ao bem-estar e que englobe as diversas dimensões do ser humano (BRASIL, 1997, p. 293).

O trabalho voltado à Orientação Sexual pode ser avaliado como o processo de intervenção sistemática, em que se busca fornecer informações sobre sexualidade, bem como organizar um espaço de reflexões e questionamentos sobre a importância da prevenção contra DSTs/AIDS e gravidez indesejada. É imprescindível, também, construir um entendimento das mudanças corporais, da construção de identidade, da importância das relações interpessoais, do valor da autoestima e do respeito às relações de gênero.

Mas, não há como negar que a disposição de questionar nosso próprio comportamento e nossas próprias conviç̧ões é sempre muito mobilizadora: para que resulte em alguma transformação, tal disposição precisará ser acompanhada da decisão de buscar informações, de discutir e trocar ideias, de ouvir aqueles e aquelas que, histórica e socialmente, foram instituídos como "outros" (LOURO, 1997, p. 145).

Aprendemos, desde a nossa tenra infância, que os órgãos genitais nos definem menino ou menina. Sequer supomos que a construção da nossa identificação como homens ou como mulheres não é um fato biológico, mas um fenômeno social e cultural. E essa ideia do corpo enquanto discurso biológico é cotidianamente repetido nos bancos escolares.

A sexualidade constitui-se em uma construção social, histórica e cultural, necessitando ser debatida na escola, a partir de discussões e da capacitação dos docentes para enfrentamento das dificuldades acerca de questões de gênero e diversidade sexual.

Estimular a pergunta, a reflexão crítica sobre a própria pergunta, o que se pretende com esta ou com aquela pergunta em lugar da passividade em face das explicações discursivas do professor, espécies de resposta a perguntas que não foram feitas. Isto não significa realmente que devamos reduzir a atividade docente em nome da defesa da curiosidade necessária, a puro vai-e-vem de perguntas e respostas, que burocraticamente se esterilizam. A dialogicidade não nega a validade de momentos explicativos, narrativos em que o professor expõe ou fala do objeto. $\mathrm{O}$ fundamental é que professor e alunos saibam que a postura deles, do professor e dos alunos, é dialógica, aberta, curiosa, indagadora e não apassivada, enquanto fala ou enquanto ouve. O que importa 
é que professor e alunos se assumam epistemologicamente curiosos (FREIRE, 1996, p. 44).

A questão ligada à sexualidade não é simplesmente o que é normal e anormal, pois existem estudos reflexivos sobre os procedimentos de inscrição dessas marcas. Há, também, a questão do corpo, mas é na cultura que características materiais adquirem sentidos. Sexualidade é uma questão processual, uma questão de vivência e experimentação. A construção do gênero e da sexualidade ocorre ao longo de toda a vida do sujeito.

Vemos, nos dias atuais, que a educação sexual trabalhada na escola é precária, abordando apenas temas voltados aos comportamentos preventivos e aos cuidados com o corpo, deixando de lado o espaço para a reflexão e formação de atitudes, que são de suma importância para entender a sexualidade humana.

Ao educador cabe a problematização sobre as questões que dizem respeito à sexualidade. A escola tem como função o desenvolvimento integral do indivíduo e não somente a transmissão do conteúdo programático. Problematizar, questionar, dialogar e compreender elementos inerentes à sexualidade como aspectos do desenvolvimento humano, constitui-se em peça fundamental para ressignificação de saberes e valores.

Orientação sexual não se abrevia no conhecimento do "sistema reprodutivo", nem no acontecimento da primeira relação sexual como supõem muitos adolescentes. Todavia, representa uma demanda de experimentação pessoal e de adensamento da cultura sexual do grupo de convivência, de suma importância na adolescência e na juventude.

A adolescência ocupa um espaço bastante significativo no conjunto das preocupações e ações que envolvem diferentes segmentos da sociedade contemporânea, entre eles, saúde, educação e políticas públicas. A sexualidade é uma manifestação psicoafetiva individual e social, a qual ultrapassa sua base biológica (sexo) e cuja expressão é normatizada pelos valores sociais vigentes. Todas as inquietações, no domínio da educação, vão além do corpo biológico, da gravidez precoce, do aborto inseguro e da prevenção das Doenças Sexualmente Transmissíveis (DSTs) e Síndrome de Imunodeficiência Adquirida (AIDS).

Fica evidente que a curiosidade e o desenvolvimento sexual do adolescente são fortemente influenciados por suas vivências, pela família, pela sua cultura e a de seus companheiros, dos vínculos que são determinantes para o seu comportamento.

A ação adotada no presente estudo, dentro do tema transversal Orientação Sexual, precisa ser considerada como o processo de intervenção metodológica que se propõe a fornecer informações sobre sexualidade, bem como organizar um espaço de reflexões e questionamentos sobre diferentes enfoques: importância da prevenção contra DSTs/AIDS e gravidez indesejada, mudanças corporais, identidade, relações interpessoais, autoestima, relações de gênero, tabus, crenças e valores a respeito de relacionamentos, comportamentos sexuais e DSTs.

\section{A formação cidadã e emancipatória do sujeito}

As crescentes mudanças sociais e culturais levam-nos a desenvolver iniciativas pedagógicas distintas no intuito de alavancar e dinamizar o processo de ensino- aprendizagem. Nesse processo, encontram-se educadores e educandos como sujeitos construtores do conhecimento com diferentes 
posições e responsabilidades, mas irmanados na busca de novas possibilidades. Tais possibilidades precisam reconhecer o processo de ensino- aprendizagem como um processo que ultrapassa os limites da sala de aula.

Os Temas Transversais Ética, Pluralidade Cultural, Meio Ambiente, Saúde, Orientação Sexual e Trabalho e Consumo inserem-se nessa ressignificação de mundo e nas experiências e curiosidades de cada sujeito envolvido, representando o alicerce para a construção e a apropriação do conhecimento. A escola necessita perceber a educação como um processo emancipatório, que faz a mediação entre as vivências dos sujeitos e o mundo. Freire (1996) chama esse processo de realidade mediadora, em que a partir da tomada de consciência, os educadores podem buscar o conteúdo programático para o ensino.

A curiosidade como inquietação indagadora, como inclinação ao desvelamento de algo, como pergunta verbalizada ou não, como procura de esclarecimento, como sinal de atenção que sugere alerta faz parte integrante do fenômeno vital. Não haveria criatividade sem a curiosidade que nos move e que nos põe pacientemente impacientes diante do mundo que não fizemos, acrescentando a ele algo que fazemos (FREIRE, 1996, p. 16).

O homem é um ser histórico-cultural capaz de transformar o mundo e a si próprio no exercício de educar-se e educar. Ao criar novas referências de mundo, o homem emerge em novas perspectivas de pensar, nas quais tem o desafio de qualificar as possibilidades a partir da prática, sempre se reavaliando e aperfeiçoando sua ação.

Ensinar exige risco, aceitação do novo e rejeição a qualquer forma de discriminação É próprio do pensar certo a disponibilidade ao risco, a aceitação do novo que não pode ser negado ou acolhido só porque é novo, assim como o critério de recusa ao velho não é apenas o cronológico. O velho que preserva sua validade ou que encarna uma tradição ou marca uma presença no tempo continua novo. Faz parte igualmente do pensar certo a rejeição mais decidida a qualquer forma de discriminação. A prática preconceituosa de raça, de classe, de gênero ofende a substantividade do ser humano e nega radicalmente a democracia (FREIRE, 2002, p. 19).

No sentido mais amplo, educação é um processo de atuação de uma comunidade sobre o desenvolvimento do indivíduo, para que ele possa atuar em uma sociedade que busca e aceita os objetivos coletivos. Para tal educação, devemos considerar o homem no plano físico e intelectual, contudo, consciente das possibilidades e das limitações, capaz de compreender e de refletir sobre a realidade do mundo que o cerca. Para isso, é preciso considerar seu papel no processo de transformação social, apreendido por intermédio de um currículo aberto e flexível que busque superar os desafios atuais, por meio da solidariedade entre as pessoas, respeitando as diferenças individuais. 
O currículo não pode ser visto simplesmente como um espaço de transmissão de conhecimentos. O currículo está centralmente envolvido naquilo que somos, naquilo que nos tornamos, naquilo que nos tornaremos. O currículo produz, o currículo nos produz (SILVA, 1999, p. 27).

Os PCNs explicitam as relações educativas como relações políticas que precisam ser construídas no coletivo da escola, colocando que a questão da democracia perpassa a organização curricular da escola. A experiência de viver na escola o exercício da democracia envolve: a gestão escolar, a comunidade a quem a escola atende, as relações entre os sujeitos que trabalham na escola, a construção do Projeto Político-Pedagógico, a convivência em sala de aula (professor/aluno; aluno/aluno), a construção do conhecimento e o reconhecimento dos alunos como cidadãos.

Por ser multifacetada, é fundamental que a educação aconteça de forma interdisciplinar com planejamento e construção a partir de decisões coletivas. É necessário que a interdisciplinaridade seja entendida como um processo, tanto individual quanto coletivo, de modo que a solução dos problemas aconteça na relação com os outros.

No processo interdisciplinar não se ensina nem se aprende, vive-se, exerce-se. A responsabilidade individual é a marca do projeto interdisciplinar, mas essa responsabilidade está imbuída do envolvimento - envolvimento esse que diz respeito ao projeto em si, às pessoas e às instituições a ele pertencentes (FAZENDA, 2005, p. 17).

Nesse sentido, o papel da educação é contribuir para o crescimento emancipatório dos educandos, por meio do desenvolvimento do pensamento crítico.

É importante preparar o homem para isso por meio de uma educação autêntica: uma educação que liberte, que não adapte, que domestique ou subjugue. Isto obriga a uma revisão total e profunda dos sistemas tradicionais de educação, dos programas, dos métodos (FREIRE, 2005, p. 45).

As intervenções sobre a realidade educacional, por mais complexas que sejam, necessitam de avaliações constantes na forma de planejamento e execução das ações, refletindo sobre o resultado das experiências dos seus agentes e de suas próprias ações. Ao desprezar a etapa do planejamento, tão importante ao processo de educação escolar, dificulta-se o ato de avaliar a construção de novos conhecimentos. Isso indica que o homem também é sujeito histórico e, como tal, é mobilizado pela transcendência, o que reflete na sua autonomia e na tomada de decisões.

\section{Temas Transversais: orientação teórica}

Os Parâmetros Curriculares Nacionais (PCNs) estabeleceram como Orientação Sexual a orientação pedagógica a ser dada à sexualidade humana nas escolas. A inclusão do tema transversal 
Orientação Sexual para ampla discussão nas escolas, sugere orientações pedagógicas fundamentadas em uma concepção propositada e politicamente construída com base na prevenção da gravidez na adolescência e das DSTs/HIV/AIDS. Sabemos da importância documental e histórica acerca da elaboração e implantação dos PCNs, mas não podemos negar que se encontram inclusos nas entrelinhas desse tema, duas questões relevantes no contexto da sexualidade: as relações entre os gêneros e o desejo afetivo-sexual.

As manifestações de sexualidade afloram em todas as faixas etárias. Ignorar, ocultar ou reprimir são as respostas mais habituais dadas pelos profissionais da escola. De fato, toda família realiza a educação sexual de suas crianças e jovens, mesmo aquelas que nunca falam abertamente sobre isso. Pode-se afirmar que no espaço privado, portanto, que a criança recebe com maior intensidade as noções a partir das quais construirá sua sexualidade na infância (BRASIL, 1997, p.112).

Partindo do pressuposto de que a sexualidade é construída por meio das relações sociais e das vivências pessoais, a educação sexual necessita abranger as discussões que envolvam diferentes enfoques norteadores das relações humanas: sociais, econômicos, éticos, étnicos e históricos. Para tanto, práticas minimizadoras, superficiais, descontextualizadas, pontuais e fragmentadas, que vigoram nas escolas devem ser revistas nos currículos escolares.

Talvez a formação dos professores que atuam em sala de aula não possibilite uma abordagem crítica e contextualizada sobre a sexualidade humana. Então, cabe salientar que educadores são sujeitos epistêmicos, pesquisadores que buscam aprofundamento teórico-prático, rescindindo com as formas superadas e descontextualizadas das ciências.

Se Foucault foi capaz de traçar uma História da Sexualidade (1988), isso aconteceu pelo fato de compreendê-la como uma "invenção social", ou seja, por entender que ela se constitui a partir de múltiplos discursos sobre o sexo: discursos que regulam, que normalizam, que instauram saberes, que produzem "verdades" (LOURO, 1997, p. 30).

Edificar homens e mulheres livres passa pelo processo de afetivação da vida sexual, pois assim os sujeitos tornam-se responsáveis e conscientes pela importância da sexualidade em suas vidas. Esse processo exige a superação da dicotomia entre corpo e alma e o reencontro do sujeito com o contexto social que o cerceia. Provoca reconhecer-se nessa totalidade, incluindo o seu sexo e a forma como sua sexualidade se expressa. Para Afonso (2001, p. 42), “[...] o jovem não apenas necessita interiorizar valores éticos socioculturais, mas, também, questioná-los, para aceitá-los ou rejeitá-los, e principalmente, para se mostrar capaz de questionamento e julgamento, provando ser um membro adulto da sociedade".

Foucault (1999, p. 27) destaca que "cumpre falar do sexo como de uma coisa que não se deve simplesmente condenar ou tolerar, mas gerir, inserir em sistemas de utilidade, regular para o bem de todos, fazer funcionar segundo um padrão ótimo. O sexo não se julga apenas, administra-se". Nessa perspectiva, os PCNs suscitam os discentes e a própria escola a produzirem a intersecção do sujeito 
consigo mesmo, estimulando o educando a enxergar-se como um elemento que requer cuidados que podem transformar seus próprios comportamentos.

Apesar dos PCNs sofrerem críticas oriundas de diferentes pensadores e esferas da educação, é inegável que estes documentos instituíram a discussão acerca da educação sexual nas escolas. Cabe, então, a cada realidade projetar o alcance sobre o entendimento e o desvelamento dos corpos e da sexualidade latente.

\section{Diálogos: aspectos teóricos e realidade dos sujeitos da escola}

Esse projeto de intervenção estruturou-se por meio de trabalhos em grupos, envolvendo as turmas de $7^{\circ}$ e $8^{\circ}$ anos do Ensino Fundamental, com treze e nove alunos, respectivamente, através de quatro etapas em sete encontros realizados nos meses de junho, julho e agosto de 2015. Em tais encontros foram abordados os temas envolvidos na questão central do trabalho: Orientação Sexual como tema transversal. Segundo Afonso (2000), esse processo não se restringe a uma reflexão racional, mas envolve os sujeitos e suas formas de pensar, sentir e agir.

Tal processo ressalta o conhecimento dos sujeitos envolvidos acerca do tema, como também a visão pessoal de mundo no espaço em que convivem, objetivando o estímulo para novas aprendizagens, que podem desencadear uma mudança significativa no pensamento em relação ao outro. As atividades desenvolvidas oportunizaram uma nova perspectiva e expressividade aos educandos, no que tange à sexualidade. Objetivou-se um maior espaço para o envolvimento com temas de interesse para que se concretizasse um real aprendizado.

Realizamos oito encontros, com duração de duas horas/aula cada. O trabalho se deu por meio da aplicação de um questionário prévio, leitura e discussão de textos informativos, recursos audiovisuais, jogos didáticos, mural interativo e palestras para a comunidade escolar. O processo continuou ao longo de um mês, em que foi utilizado como material didático em sala de aula o livro "Os 15 anos de Mariana: um convite a outras aprendizagens sobre os corpos", produzido pelos integrantes do Grupo de Estudos e Pesquisas em Educação em Ciências (GEPEC) em parceria com pesquisadores e pesquisadoras da FURG.

\section{- Primeira etapa: aplicação do questionário}

Um questionário prévio foi aplicado para levantamento do conhecimento dos alunos referente ao tema. Gil (2002) afirma que o uso de questionários é uma técnica de investigação formada por perguntas apresentadas por escrito e destinadas às pessoas que se deseja questionar. O questionário aplicado procurou delinear o perfil dos sujeitos com base nas suas vivências e de como acessam as informações consoantes a sua sexualidade em 14 questões.

Por isso, mesmo pensar certo coloca ao professor ou, mais amplamente, à escola, o dever de não só respeitar os saberes com que os educandos, sobretudo os das classes populares, chegam a ela - saberes socialmente construídos na prática comunitária - mas também, como há mais de trinta anos venho sugerindo, discutir com os alunos a razão de ser de alguns desses saberes em relação com o ensino dos conteúdos (FREIRE, 2002, p. 17). 
O processo envolveu 16 educandos do sexo masculino e 06 do sexo feminino, perfazendo um total de 22 educandos dos anos finais ( $7^{\circ}$ e $8^{\circ}$ anos) do Ensino Fundamental. Das 14 questões, foram selecionadas 12 questões com maior representatividade para nortear o trabalho. Os discentes estão na faixa etária entre onze e dezessete anos. Quando perguntados "Você está feliz com o seu corpo?" 68\% afirmam estar felizes com seu corpo, $27 \%$ declararam-se "mais ou menos" felizes e $5 \%$ estão infelizes com o seu corpo.

Na questão "O que o namoro entre pessoas do mesmo sexo representa para você?", 81\% considera uma escolha sexual normal de cada um, 14\% pensam ser algo absurdo e inaceitável e 5\% consideram uma doença.

A questão seis do questionário aponta nove alternativas, todas relacionadas à sexualidade, os alunos deveriam responder: "Dos temas abaixo, quais estão relacionados com a sexualidade?" 91\% dos educandos apontaram a gravidez, $89 \%$ a virgindade, $68 \%$ as DSTS, $63 \%$ a homossexualidade, $54 \%$ atração, $51 \%$ os métodos contraceptivos, $41 \%$ a prostituição, $27 \%$ o preconceito e $18 \%$ a autoestima.

As alternativas apontadas na questão seis foram repetidas na questão oito, na qual o aluno responderia sobre "Quais temas já foram abordados?" 73\% marcaram DSTS e gravidez; $68 \%$ preconceito e homossexualidade, $54 \%$ virgindade, $41 \%$ métodos contraceptivos, $36 \%$ autoestima, $32 \%$ prostituição e $23 \%$ atração.

Na questão nove, eles deveriam assinalar as alternativas que respondessem "De que forma seus professores trabalham temas relacionados à orientação sexual em sala de aula?" Foram obtidas as seguintes respostas: 73\% através de filmes e/ou documentários, $68 \%$ em debates em sala de aula, $41 \%$ através de palestras, $13 \%$ com o apoio de textos e/ou livros didáticos, $9 \%$ através de trabalhos e pesquisas e $5 \%$ por intermédio de revistas e/ou histórias em quadrinhos.

A questão dez indaga: "Você se sente à vontade para perguntar aos seus professores dúvidas acerca de sexualidade?" 41\% indicaram que "mais ou menos, dependendo do tema", $31 \%$ responderam que "sim, sem problemas" e 27\% "não perguntam por terem vergonha".

Questionados na pergunta onze sobre: "Com quem você conversa sobre sexualidade?", obtiveram-se as seguintes respostas: $54 \%$ não conversam com ninguém, $36 \%$ com a professora de Ciências, $18 \%$ com os pais e $14 \%$ com amigos e colegas.

A questão doze indaga: "Quais os meios que você utiliza para tirar suas dúvidas sobre sexualidade?" $68 \%$ recorrem à internet, 36\% buscam em programas de TV, 13\% em livros, 9\% em revistas, $5 \%$ em jornais e $5 \%$ não procuram informações. Quando questionados se consideravam as informações passadas pela mídia confiáveis, $41 \%$ indicaram ter dúvidas sobre as fontes das informações, $32 \%$ não consideram confiáveis e $27 \%$ confiam nas informações.

Para finalizar o questionário, perguntou-se aos educandos: "Você considera importante a orientação sexual ser trabalhada na escola?" 95\% responderam que sim e 5\% não consideram importante trabalhar esse tema a escola.

\section{Segunda etapa: Textos informativos e discussões}

No primeiro encontro, os alunos foram divididos em dois grupos: cada grupo recebeu um texto para leitura e apresentação. Um texto tratava da questão de prevenção à DSTs e gravidez, o outro apresentava aspectos referentes às diferentes orientações sexuais. Após a leitura e discussão nos grupos, passamos para as apresentações, em que os alunos demonstraram dificuldades para se expressar. Diante disso, foram propostas questões específicas para que cada grupo pudesse expor suas apreensões sobre 
o texto. Ao responder as questões, os alunos passaram a participar voluntariamente da discussão, mostrando-se bastante interessados.

O educador libertador tem que estar atento para o fato de que a transformação não é só uma questão de métodos e técnicas. Se a educação libertadora fosse somente uma questão de métodos, então o problema seria mudar algumas metodologias tradicionais por outras mais modernas. Mas não é esse o problema. A questão é o estabelecimento de uma relação diferente com o conhecimento e com a sociedade (FREIRE, 1986, p. 28).

Surgiram comentários do tipo "gay nasce gay e não adianta!", "que nojo!"; muitos comentários preconceituosos. Uma aluna salientou que sua mãe é casada com uma mulher e que isso não a prejudicou em nada. Frente a tais manifestações, percebe-se que o preconceito encontra-se enraizado na família, estendendo-se a outros espaços sociais, sendo frequente o uso apelidos homofóbicos entre os alunos.

O maior interesse foi referente à questão de prevenção à DSTs e gravidez indesejada, as perguntas e discussões fluíram com bastante naturalidade. Apresentaram dúvidas sobre os métodos anticoncepcionais e o uso de preservativo. Ficou evidente que esse assunto ainda é tratado como um tabu entre pais e filhos.

\section{Terceira etapa: Vídeos}

Foram apresentados quatro vídeos: Cenas da vida 1, que fala a respeito da relação afetiva e sexual entre pessoas do mesmo gênero; Cenas da Vida 2, que discute a gravidez na adolescência, abordando a responsabilidade do menino e da menina na prevenção; Rap da Prevenção que trata da prevenção contra DSTs e gravidez indesejada (DVD: Sexualidade, tá ligado?) 3 e "Diversity Inclusion - Love has no label", que trata do preconceito contra as diferenças.

Após a apresentação de cada vídeo, abriu-se espaço para debate e discussão sobre o aquilo que foi visto. Os alunos mostraram-se atentos à utilização de uma nova tecnologia, pois, na escola não há recursos multimídias. O conteúdo dos vídeos atraiu a atenção, o que ficou evidente em suas expressões faciais, que variaram entre a admiração e o desprezo.

Para os alunos de menos idade, o vídeo mais atrativo foi o que trata da gravidez na adolescência. Talvez pelo fato de que na escola, duas meninas jovens são mães, isso os deixa muito impressionados. Percebe-se que essas meninas apresentam um comportamento bastante infantil e carregam muitas dúvidas em relação ao seu corpo. Esse comportamento, sem dúvida, é fruto da falta de diálogo e de orientação por parte dos pais e da própria escola.

Houve comentários do tipo: "se a menina fica grávida, acaba a vida dela"; "aborto não é legalizado no Brasil, só em caso de estupro"; "o que custa usar camisinha: dão até no posto", "é normal o pai não querer o filho", "homem não é bichinha para se preocupar com camisinha", "na hora do lepo-lepo não tem frescura", já uma aluna enfatizou "se fosse só a vida dos pais não era nada, pior é largar um filho no abrigo".

${ }^{3}$ DVD: Sexualidade, tá ligado? Projeto Sexualidade e Escola: discutindo práticas educativas. Grupo de Pesquisa Sexualidade e Escola (GESE), Universidade Federal do Rio Grande - FURG. 
A sexualidade é parte natural no processo de desenvolvimento biopsicossocial dos seres humanos. Vemos que em muitos lares e nos bancos escolares, as questões sexuais dos adolescentes são negligenciadas pela família e pelos educadores, como se fossem elementos distantes do processo de formação do aluno-cidadão. A sociedade moderna vem constantemente atravessando transformações, seja no campo da economia, da política e social. Essas transformações favoreceram o desgaste dos valores éticos e morais que circundam entre os jovens atualmente. Os educandos recebem excesso de informações banais sobre sexo através da internet, revistas, filmes e programas de TV. A falta de diálogo nas famílias gerou certa liberação sexual calcada na falta de limite e responsabilidade. Consequentemente, essa falta de diálogo nos lares somada à falta de limites e responsabilidades são alguns dos motivos que favorecem a incidência de gravidez na adolescência.

Em relação ao vídeo Cenas da Vida 1, as opiniões ficaram bem divididas: alguns entendem "que cada um faz o que quer da vida", outros não quiseram nem falar sobre o assunto, ainda houve alunos que, durante o vídeo, comentaram: "são sapatonas"; "vai agarrar a amiga também"; "melhor duas gurias do que dois viados". Fica claro, mais uma vez, que a questão de identidade de gênero gera bastante desconforto ao ser tratada de forma vulgar e preconceituosa. Ousamos afirmar que tanto o sexismo como as atitudes preconceituosas deseducam e entravam a formação de homens e mulheres, independente de sua opção sexual.

O Rap da Prevenção agradou a todos, sendo que até acompanharam alguma parte da música, que é bastante atual, tendo a linguagem usual deles e uma fotografia bem atrativa. Acharam "melhor que MC. Biel!"

O vídeo "Diversity Inclusion - Love has no label" encantou a maioria dos alunos por mostrar a diversidade e a inclusão cujo tema central era o amor sem rótulos. Surgiram testas franzidas quando apareceram na tela um casal de mulheres e um casal de homens com um filho. Alguns alunos pediram para repetir o vídeo, confirmando o quanto apreciaram.

Sabemos que não é a educação que modela a sociedade, mas, ao contrário, a sociedade é que modela a educação segundo os interesses dos que detêm o poder. Se é assim, não podemos esperar que a educação seja a alavanca da transformação destes últimos. Seria ingênuo demais pedir à classe dirigente no poder que pusesse em prática um tipo de educação que pode atuar contra ela (FREIRE, 1986, p. 29).

\section{Quarta etapa: Jogos didáticos}

Os jogos didáticos constituem uma ferramenta capaz de revigorar o ensino, interdisciplinarmente, mobilizando novas provocações e novos desafios à escola. Faz parte desse trabalho de pesquisa e intervenção o uso de jogos, pois o tema transversal: Orientação Sexual exige capacidade de abstração, o que pode ser facilitado quando trabalhado por meio de jogos didáticos. Cunha (1998) sugere que o jogo pedagógico ou didático é aquele concebido com o objetivo de propiciar determinadas aprendizagens, diferenciando-se do material pedagógico por seu aspecto lúdico.

Entendemos que os jogos adquirem amplo espaço como ferramenta de aprendizagem, pois levam o educando a pensar e a compartilhar experiências, aproximando-o do conhecimento científico de maneira lúdica e prazerosa. 
Ao subordinar todo o comportamento a certas regras convencionais, ele é o primeiro a ensinar uma conduta racional e consciente. (...) O jogo é a primeira escola de pensamento. Todo pensamento surge como resposta a um problema, como resultado de um novo ou difícil contato com os elementos do meio (VYGOTSKY, 2003, p. 107).

O jogo se apresenta carregado de conteúdos culturais e de experimentações pessoais dos sujeitos. A apreensão dos conteúdos se dá por meio de interações e das práticas sociais. Ojogo, por estar carregado de aprendizagem, provoca no educando a curiosidade, promovendo o desenvolvimento.

Foram apresentados três jogos, em datas distintas nas turmas envolvidas, em que se buscava discutir questões abrangentes sobre corpo, gênero e sexualidade: "Fala sério ou com certeza?", "Bingo" e "Trilha da Orientação Sexual". Os jogos não foram programados acerca do corpo biológico apenas, mas cunhado nas diferenças e vivências de cada sujeito.

Enquanto prática social a prática educativa, em sua riqueza, em sua complexidade, é fenômeno típico da existência, por isso mesmo fenômeno exclusivamente humano. [...] Ao inventar a existência, com os "materiais" que a vida lhes ofereceu, os homens e as mulheres inventaram ou descobriram a possibilidade que implica necessariamente a liberdade que não receberam, mas que tiveram de criar na briga por ela. Seres indiscutivelmente programados, mas, como salienta François Jacob1, "programados para aprender", portanto seres curiosos, sem o que não poderiam saber, mulheres e homens se arriscam, se aventuram, se educam no jogo da liberdade (FREIRE, 2001, p. 34, grifo do autor).

"Fala sério ou com certeza" - Nesse jogo, cada pergunta constitui uma afirmação: se essa estivesse correta, a resposta seria: "Com certeza", se estivesse errada, a resposta seria: "Fala sério" e o grupo deveria apontar a asserção verdadeira. Cada acerto equivalia a um ponto e os erros não pontuavam.

O material utilizado foi: um dado com três lados vermelhos e três lados azuis, 14 cartas azuis e vermelhas (com as questões), 4 minicartazes com as frases "fala sério e com certeza", quadro branco e caneta para quadro branco. Cada equipe escolheu o seu líder e as regras foram passadas e discutidas: "par ou ímpar" para ver quem começaria; o jogador deveria jogar o dado e conforme a cor do lado em que caísse, seria a cor da carta que deveria retirar; a professora faria a leitura da pergunta contida na carta; todos os componentes da equipe deveriam responder, um de cada vez, a uma questão, levantando o minicartaz com a resposta, todos teriam um minuto para responder, valendo um ponto para acerto. Venceria a equipe que pontuasse mais.

Bingo - A turma foi dividida em dois grupos, para responderem as questões que estavam dentro dos envelopes do cartaz com a palavra "BINGO" no sentido horizontal e com numeração de 1 a 5, no 
sentido vertical, fechando um total de 25 questões dissertativas. Após a explanação e discussão das regras, um aluno deveria escolher uma letra da palavra bingo e um número de 1 a 5 e no envelope correspondente ao "cruzamento", dessa escolha teria uma questão a ser lida pela professora e respondida pelo aluno. Cada acerto corresponderia a um ponto, já cada erro implicava perda de um ponto.

Trilha da Orientação Sexual - Esta atividade foi realizada no pátio da escola e a trilha foi realizada com a numeração de 1 a 10 (ida e volta), marcada no chão nas cores vermelho e azul, um dado gigante para cada grupo e um marcador para cada jogador.

A pedido dos educandos, esse jogo deu-se interséries ( $7^{\circ}$ ano versus $8^{\circ}$ ano). As regras foram apresentadas: cada jogador, na sua vez, jogava o dado: o número que caísse, correspondia a uma questão e o acerto ao avanço de uma casa. A participação dos discentes foi efetiva e entusiasta. Tamanhos foram o envolvimento e a empolgação dos participantes, que causou surpresa e sensação real de conquista. As respostas eram dadas com precisão e solidez, os erros não foram consideráveis em relação aos acertos e argumentações. Após a realização dos jogos, sempre apareciam mais ideias e discussões.

\section{Quinta etapa: Mural interativo}

Nesse mural, intitulado "Prazer em conhecê-lo!", os alunos responderam questões de caráter pessoal do tipo: apelido, maior qualidade, uma "bizarrice", o que gosta de fazer nas horas vagas, cor preferida, um animal, time do coração, entre outras. Cada entrevista foi colada no mural, assim como a foto identificando cada discente; os murais das turmas do $7^{\circ}$ e $8^{\circ}$ anos foram expostos nos corredores da escola para que os estudantes "se apresentassem" para a escola. O propósito dessa atividade foi fazêlos compreender que seus gostos pessoais os fazem sujeitos únicos, ao mesmo tempo em que atuam nas vidas de outrem.

Uma das tarefas mais importantes da prática educativo-crítica é propiciar as condições em que os educandos em suas relações uns com os outros e todos com o professor ou a professora ensaiam a experiência profunda de assumirse. Assumir-se como ser social e histórico, como ser pensante, comunicante, transformador, criador, realizador de sonhos, capaz de ter raiva porque capaz de amar. Assumir-se como sujeito porque capaz de reconhecer-se como objeto. A assunção de nós mesmos não significa a exclusão dos outros. É a "outredade" do "não eu", ou do $t u$, que me faz assumir a radicalidade de meu eu (FREIRE,2002, p. 22).

Como ensina Freire, com paciência e sabedoria, esse movimento é que faz a transformação e o crescimento de um cidadão, pois enfatiza a importância de o educando assumir-se como sujeito e de reconhecer-se sem que, para isso, haja necessidade de promover a exclusão do outro.

\section{Considerações finais}

Trabalhar o tema transversal Orientação Sexual sublimou a provocação dos sujeitos participantes: sua conjuntura propiciou a reflexão sobre a importância do diálogo, da escolha em exercer a sua sexualidade, em função da vida e da integridade do "ser pessoa", como parte determinante do 
papel do sujeito na sociedade. Cabe à escola buscar práticas interdisciplinares adequadas para que sua tarefa em empenhar-se na educação sexual não se torne superficial e/ou pontual, invalidando o interesse do educando. Os Temas Transversais são o norte e o potencial dos temas morais, cabendo aos educadores e aos gestores o julgamento do que fazer em relação a trabalhá-los ou não na escola. Para tanto, o tema transversal da Orientação Sexual necessita perpassar todos os componentes curriculares do Ensino Fundamental, articulando as diversas áreas do conhecimento.

Para o professor, escola não é apenas lugar de reprodução de relações de trabalho alienadas e alienantes. É, também, lugar de possibilidade de construção de relações de autonomia, de criação e recriação de seu próprio trabalho, de reconhecimento de si, que possibilita redefinir sua relação com a instituição, com o Estado, com os alunos, suas famílias e comunidades (BRASIL, 1997, p. 53).

A pesquisa de intervenção escolar possibilitou-nos transcender a postura de "repassar" informações. A cátedra da transversalidade não é disciplinar, difunde-se na interdisciplinaridade, mediando a relação intrínseca do sujeito com o seu pensar e o seu agir, na construção de novas posturas e novos comportamentos. A sexualidade precisa ser vista como um dos componentes essenciais para o desenvolvimento saudável do indivíduo, por isso, não pode ser desprezada dentro do processo educativo.

É preciso insistir: este saber necessário ao professor - que ensinar não é transferir conhecimento - não apenas precisa de ser apreendido por ele e pelos educandos nas suas razões de ser - ontológica, política, ética, epistemológica, pedagógica, mas também precisa de ser constantemente testemunhado, vivido (FREIRE, 2002, p. 25).

As provocações e diálogos pautados na sexualidade são de suma importância para que se estabeleça um clima de respeito em uma sociedade que possa viver e conviver com as diferenças. Temos consciência do quão importante é o respeito às diferentes formas de pensar e agir dos sujeitos, para a construção de uma educação orientada pela autonomia e emancipação dos cidadãos e cidadãs.

Mas, não há como negar que a disposição de questionar nosso próprio comportamento e nossas próprias conviç̧ões é sempre muito mobilizadora: para que resulte em alguma transformação, tal disposição precisará ser acompanhada da decisão de buscar informações, de discutir e trocar ideias, de ouvir aqueles e aquelas que, histórica e socialmente, foram instituídos como "outros" (LOURO, 1999, p. 145). 
A priori, verificamos que os alunos refletem, de modo significativo, as experiências trocadas entre eles. A despeito disso, houve mudanças em suas atitudes, empenharam-se em mostrar que entenderam a importância do tema para sua formação, evidenciando uma postura de comprometimento consigo, com o outro e com o processo vivenciado. Uma das maiores conquistas desse processo de intervenção foi justamente resgatar o respeito à individualidade entre os discentes. O diálogo aberto voltado às suas necessidades fez com que os alunos criassem um vínculo maior com o projeto, ficando mais desinibidos para dialogar e sanar suas dúvidas, expondo seus receios e suas perspectivas em relação à sexualidade.

Eleger a conscientização e a promoção de uma educação emancipatória significa priorizar a formação cidadã consciente e crítica, trazendo a possibilidade da transformação social, que possa resultar em liberdade, responsabilidade e autonomia.

\section{Referências}

AFONSO, Lúcia. A polêmica sobre adolescência e sexualidade. Belo Horizonte: Ed. do Campo Social, 2001.

BECKER, Fernando. A Epistemologia do Professor: o cotidiano da escola. Petrópolis: Vozes, 1993.

BRASIL. Ministério da Educação e do Desporto. Secretaria de Educação Fundamental Parâmetros Curriculares Nacionais: pluralidade cultural e orientação sexual. Brasília: MEC/SEF, 1997. v. 10.

CUNHA, Nylse Helena da Silva. Brinquedo, desafio e descoberta: subsídios para a utilização e confecção de brinquedos. Rio de Janeiro: FAE, 1988.

FAZENDA, Ivani (Org.). Práticas Interdisciplinares na Escola. 10. ed. São Paulo: Cortez, 2005.

FOUCAULT, Michel. Vigiar e Punir: Nascimento da Prisão. 27. ed. Petrópolis: Vozes, 1999.

FREIRE, Paulo. Medo e Ousadia: O Cotidiano do Professor. 18. ed. São Paulo: Paz e Terra, 1986.

FREIRE, Paulo. Conscientização: teoria e prática da libertação: uma introdução ao pensamento de Paulo Freire. São Paulo: Centauro, 2001.

FREIRE, Paulo. Pedagogia da Autonomia: saberes necessários à prática educativa. 25. ed. São Paulo: Paz e Terra, 2002.

FREIRE, Paulo. Pedagogia do Oprimido. 43. ed. Rio de Janeiro: Paz e Terra, 2005.

LOPES, Maria da Glória. Jogos na Educação: criar, fazer, jogar. 2. ed. São Paulo: Cortez, 1999. 
LOURO, G. L. Gênero, sexualidade e educação. Uma perspectiva pós-estruturalista. Petrópolis, RJ: Vozes, 1997

RIBEIRO, Paula R. C.; LONGARAY, Deise A. (Org.). Os 15 anos de Mariana: um convite a outras aprendizagens sobre os corpos. Rio Grande: FURG, 2013.

RIBEIRO, Paula R. C.; QUADRADO, Raquel. P. (org). Corpos, gêneros e sexualidades: questões possíveis para o currículo escolar. 3. ed. Rio Grande: FURG, 2013

SILVA, Fabiane Ferreira et al. Sexualidade e escola: compartilhando saberes e experiências. 3. ed. Rio Grande: FURG, 2013.

SILVA, Tomaz T.O currículo como fetiche. Belo Horizonte: Autêntica, 1999.

VYGOTSKY, Lev S. Psicologia Pedagógica. Edição comentada. Porto Alegre: Artmed, 2003. 